\title{
Internet of Things: A Product Development Cycle for the Entrepreneurs
}

\author{
${ }^{\text {"1 } V i k r a m ~ N e e r u g a t t i, ~}{ }^{2}$ Dr. K.K. Baseer, ${ }^{3}$ Dr. M. Jahir Pasha, ${ }^{4}$ V. D. Satish Kumar \\ ${ }^{1}$ Department of Computer Science and Engineering, Sree Venkateswara College of Engineering and \\ Technology, Chittoor \\ ${ }^{2}$ Department of Computer Science and Engineering, Sree Vidyanikethan Engineering College, Tirupati \\ ${ }^{3,4}$ Department of Computer Science and Engineering, Dr. K. V. Subbareddy College of Engineering for \\ Women, Kurnool. \\ Email: vikramneerugatti@gmail.com,drkkbaseer@gmail.com,jahir4444@gmail.com,drkvsreddy@gmail.com
}

Received: 06th December 2019, Accepted: 20th January 2020, Published: 30th April 2020

\begin{abstract}
Internet of Things (IoT) is a current technology in the communication and computing field. With the help of this technology many application can be developed almost in every fields like health care, agriculture, education manufacturing, factories, automobile etc. In this fields the applications can be like smart home, smart office, smart farms, smart utilities, smart boards, smart vehicles, smart machines etc. To develop this kind of applications already many IOT startup companies are evolved. The current paper proposed a novel IOT product development cycle which will make easy for the developers in the IOT startup companies/individuals and in this paper few developed products based on the proposed development cycle were discussed.
\end{abstract}

Keywords

IOT, Development Cycle, IOT Products, Smart Internet of Things.

\section{Introduction}

IOT is a new computing and communication paradigm which is used to extend the internet to the real time objects [1]. The real time objects may be any object around us like chair, table, light, fan etc. In IOT technology for every object has a unique identity which is used to communicate among each other locally and globally. This connectivity among objects will leads to many applications in almost every field in the world. This IoT is possible with the help of the sensors, microprocessors, micro controllers, cloud computing, actuators etc. Sensors will work the way, how the Sense organs of human will work similar to the Sense organs of human being we have seeing sensor, hearing sensors, tasting sensor, feeling sensor, smelling sensor for example the sensors like camera, sensor, mike sensor, speaker, light, PIR, LDR, temperature, pressure, proximity, MQ135, MQ6, MQ5, vibrator etc. Every sensor requires a power that will be supplied from the microcontroller/microprocessor.

The micro-controller or microprocessor will act as a brain like a CPU of a computer it will take the input from various sensors and then to processor with the help of the microprocessor in it and sends output with the help of actuators, few of the micro controller and microprocessor are, arduino, node MCU, Raspberry pi, Intel Edison, chip cat, Texas's instruments, Intel Galileo etc.. This requires a power which will be supplies directly from the power-unit with the help an adapter. Actuators are the things in the real world for example fan, AC, refrigerator, chair, table etc. These things will activate with the help of micro controller/microprocessor based on the sensors as an input defined by the user's requirement. 


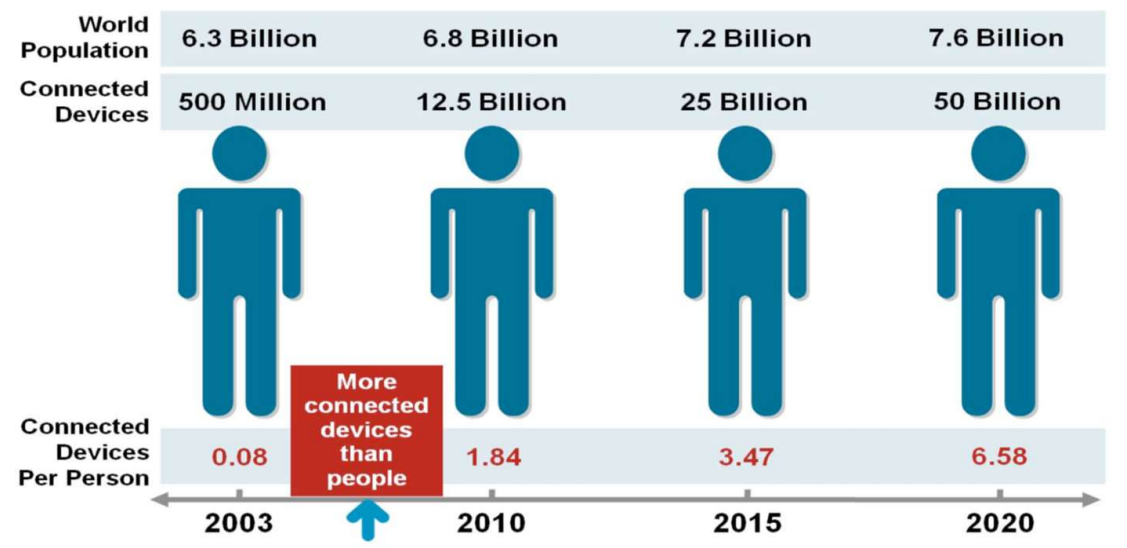

Fig. 1: Internet of Things Started at 2009.

Source: Cisco white paper 2011.

The phrase IOT was called by Kevin Ashton in 1999 at MIT [5]. Most of the objects will be in online with this technology [6]. All the values they get from the sensors and the activities of the actuators will be stored in the cloud servers online (Things Speak). This data will help to take the wise decisions for the users of the IoT applications for example the rate of the power units can be decided based upon the usage of the customer. Based upon the usage of the customer the Electricity light can be rented for the hours. Cisco predicted that by 2020 the connected devices will become 50 Billion and 1 person 6.58 devices will be connected [2] as shown in Fig. 1. This prediction itself says that the internet of things has more market value in the development of IoT Applications. In connection of this many of IoT startup companies has evolved in almost every field. This paper proposed a novel development cycle for development of IOT applications and products named as AMBATIARR.

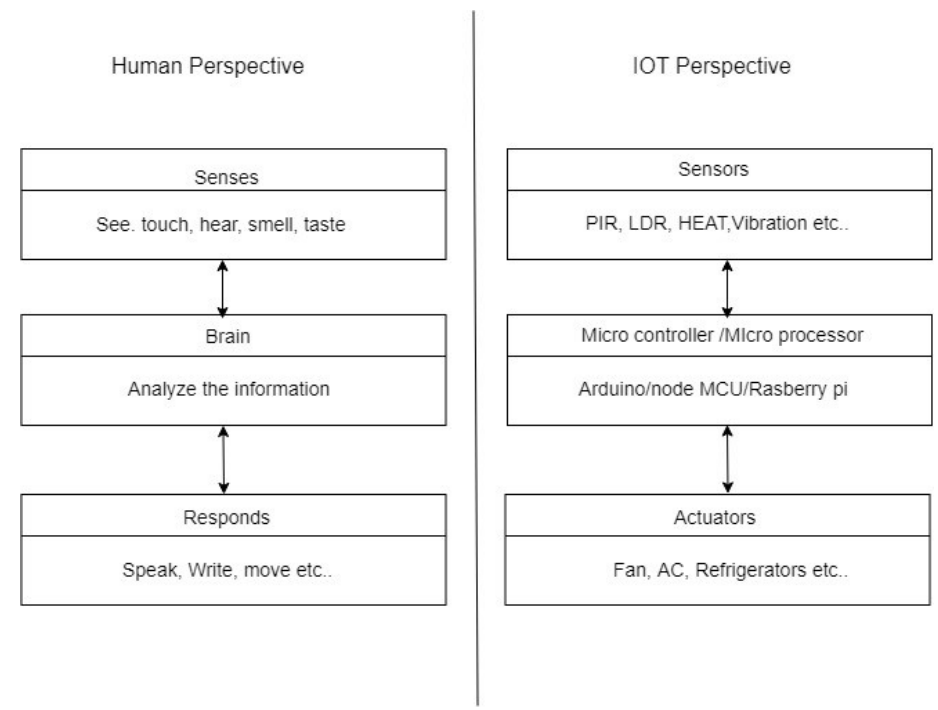

Fig. 2: Sense-Analyze-Act

The next sections of the paper is discussed as follows, in section 2 discussed about related work, proposed system is discussed in section 3, developed products based on proposed development were discussed in section 4 and in section 5 concluded the paper.

\section{Related Work}

In paper [3] authors has proposed a frame work manufacturing further 3D printing and concluded that the IOT has an effect in the industries of manufacturing, development units. In paper [4] authors proposed a business model to do business in the area of IOT. In paper [6], authors discussed about the IOT role in the entrepreneurship and how it impacts in everyday life.

\section{Proposed Development Cycle}

The proposed system has a different phase like hardware, software, integrating with cloud and android app, testing, deployment, packing and marketing. The development cycle was shown in Fig 3. The figure indicates the clear development cycle to develop any IOT product. 
In the hardware phase the developers should be clear with the circuit diagram, sensors to be used, to select the type of microcontroller or microprocessor, actuators to be used. Once clear with the requirements as per the circuit diagram, need to be placed on the PCB, with the help of soldering rod and wire. To ensure that the circuit diagram on the PCB was correct need to be checked with the multi-meter. In the software phase depending upon the user requirements need to write the algorithm, flowchart based on that algorithm, coding should be done in $\mathrm{c}$ or python programming languages. In the arudino IDE, once the code was verified the developed hardware kit was connected to the laptop and the code verified in the Arduino IDE was uploaded to the developed hardware.

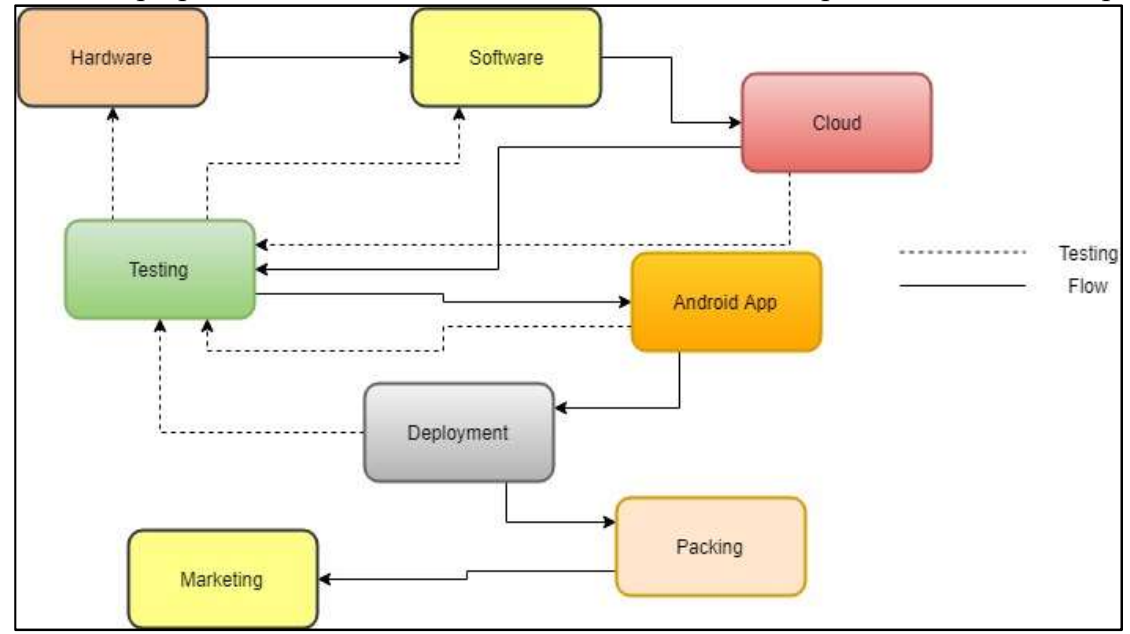

Fig. 3: Internet of Things Product Development Cycle

In the testing phase the testers will be checked whether the software or hardware after integrating together, will meet the requirements of user or not. Similarly the testers will check the cloud connectivity and the android app and the deployment phase, whether the work was done right or not. In the cloud phase after the completion of the hardware and software phases the IoT Product will be integrated to the cloud platform. One of the platforms can be used by IOT developers are Thing Speak cloud platform. In the Thing Speak cloud platform to connect the developed kit channel should be created, after creation of channel, the sensors and actuators can be added by using that channel ID's once the developed product connected to the things peak the values can be analyzed in the things peak cloud platform with the help of mat lab graphs, then can be acted/triggering based on the values. In the android phase for the remote controlling and monitoring the developed product android app should be developed for the easy interfacing with the users the android apps can be developed with the help of android studio or MIT inventor. Once the app developed that can be placed in play store where the clients can be downloaded easily to their mobiles. In the deployment phase moulding/casing should be done for the developed product for security purpose or safe guarding, on the casing the IOT startups can put their own logo and other details. In the packing phase the developed product should be placed inside the packet cover along with the user manual and the guaranty and warranty card. In marketing phase once the product developed, to take the product to the customers can be done direct marketing, dealership model and franchise model and can give the various types of advertisement for sales.

By this proposed development cycle it is clear for the entrepreneurs that how to develop the IoT product and to develop an IOT product we require the employees as hardware developers those who have skill in soldering, identifying the sensors, microcontrollers, actuators etc. Software developers, that who has knowledge in c, python language and about arduino IDE. Cloud analysts that who has skill to integrate the hardware kit, with the cloud platform (thing Speak) and with basic programming language skills. Android developers that who have skill to develop the apps by using the android studio or MIT app inventor with basic programming skills. Testers, those who have skill in all phases like hardware, software. Cloud, android deployment and packing. Deployment Engineers has basic knowledge about the molding and the casing and the packers has basic skills of packing and finally the marketing managers, to promote the developed products to various customers can recruit the trainers for training the fresher's and can recruit the researchers to innovate the new products.

\section{Developed Products:}

By using the proposed development cycle various product has been developed few of the products was discussed in this section

\section{A. Product 1: Smart School Bus}

The aim of the smart school bus is to track the school bus by the parents and the management of the school in order to avoid the waiting time and remote monitoring the school bus. Generally at the pickup points and drop points the parents not known the exact location/exact time of the bus so by using this product they can track the 
exact location of bus for smooth transportation for the students here the GPS sensor with the Wi-Fi enabled micro controller/GSM chip was placed in the bus with the help of that the values will be moved to the cloud platform from there the latitude, longitude and with exact location of the bus will send to the parents mobile/management of schools.

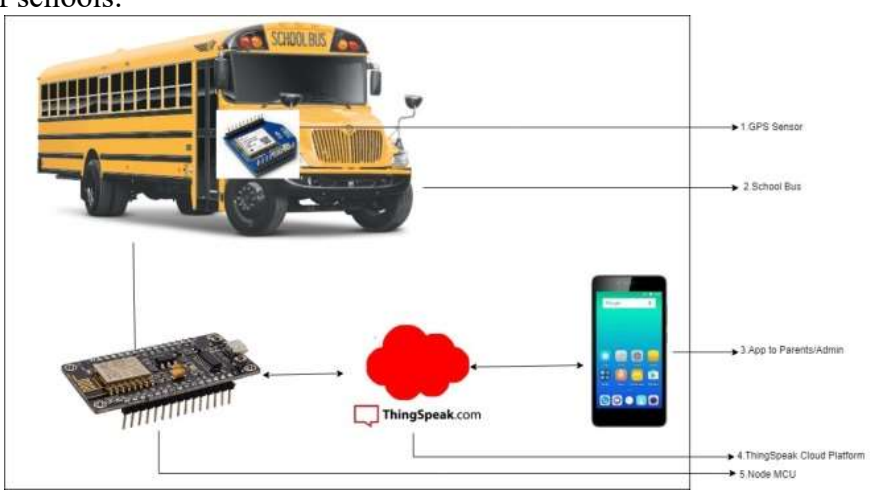

Figure 4: Smart School Bus

\section{B. Product 2:Smart LPG gas detector:}

The aim of this product is to detect the leakage of the LPG gas from the gas cylinder/gas pipeline. Whenever the gas got leaked immediately with the help of the gas detection senor MQ6 will sense it and for the local intimation the message will be sent to the registered mobile.

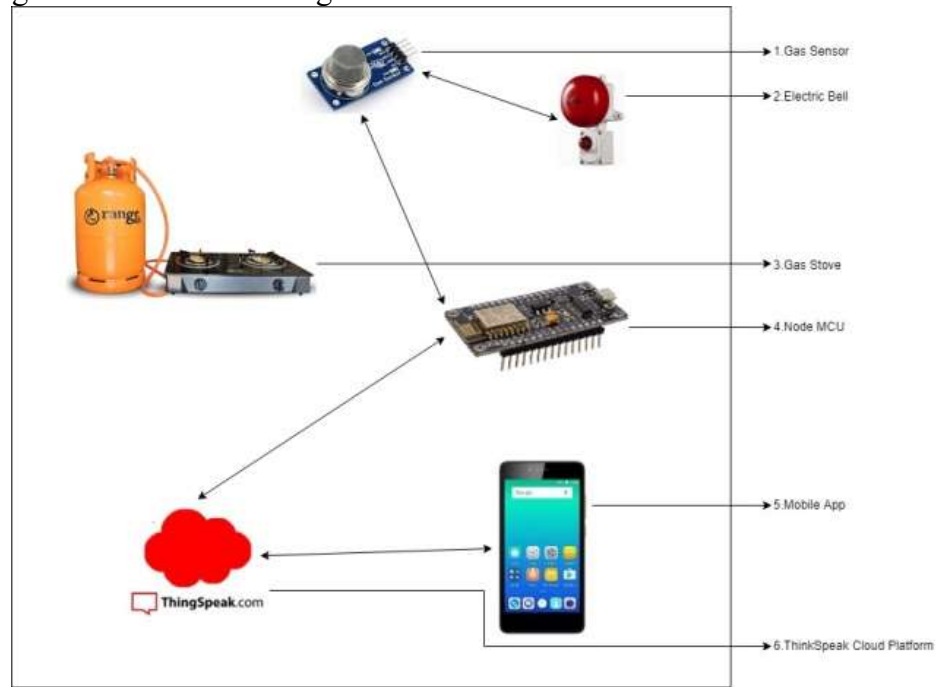

\section{Product 3: Smart ID Card}

Figure 5: Smart LPG Gas

The aim of this product is to track the student or employee location during the working hours and can decide the attendance for students and salary for the employees here in the ID card the RFID sensor and the GPS sensor was implanted and connected to the microcontroller which will process the information and the data is send to the cloud the cloud we can crack the locations of the students/employee minute/weekly/hourly/monthly/yearly.

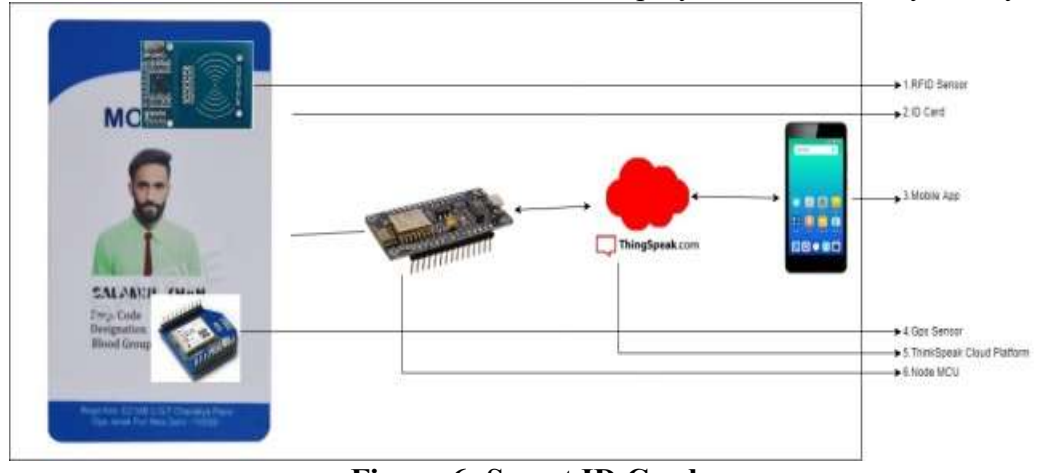

Figure 6: Smart ID Card 


\section{Product 4:Smart Switch}

The aims of this product are to remote control and monitor the home appliances like fridge, geezer, AC, fan etc. Here the sensors was used for automatic detection of the light and the presence of human being to switch on the home appliances like light fan, AC, TV etc.. And can be controlled remotely from any place in the world. The duration of the usage of the each and every home appliances can be calculated in the cloud platform and based upon the usage we can set the rate

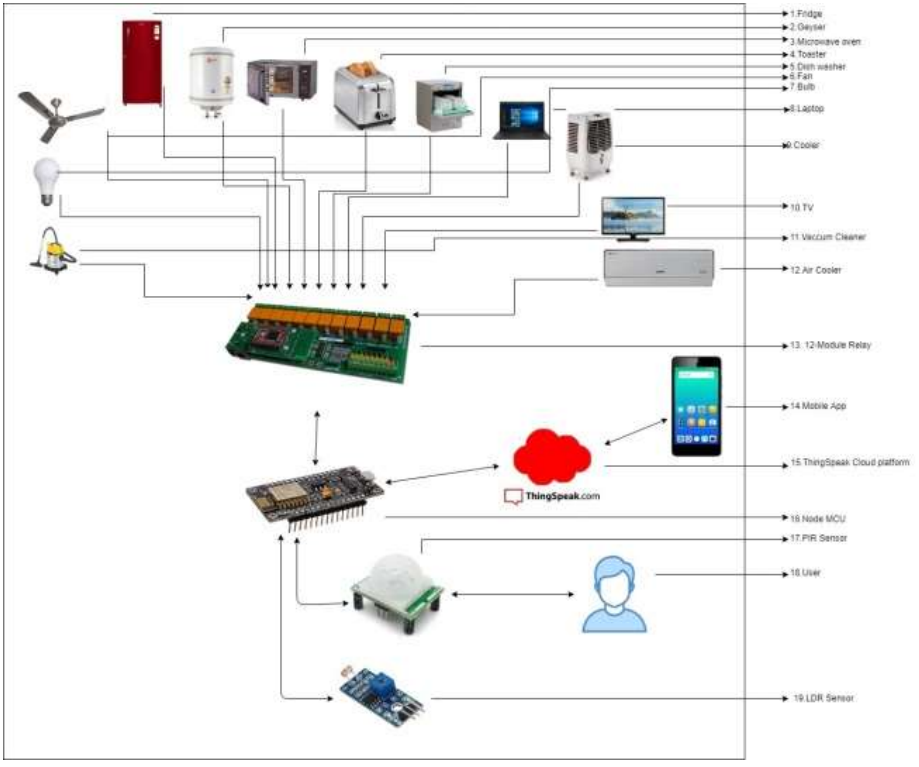

Figure 7: Smart Switch

\section{E. Product 5:Smart Basket}

The aim of this product is to automatically detect the name of the item, prize and automatically pay the money to the vendor in the supermarket to avoid the queue lines. Here the Bluetooth, RFID and weight sensor was implanted to the basket which is used to read the item and displace the cost and weight of the product in the mobile app that which connected to the Bluetooth trolling and will store the items in cloud and based upon that item the supermarket can give individual offers to the customers.

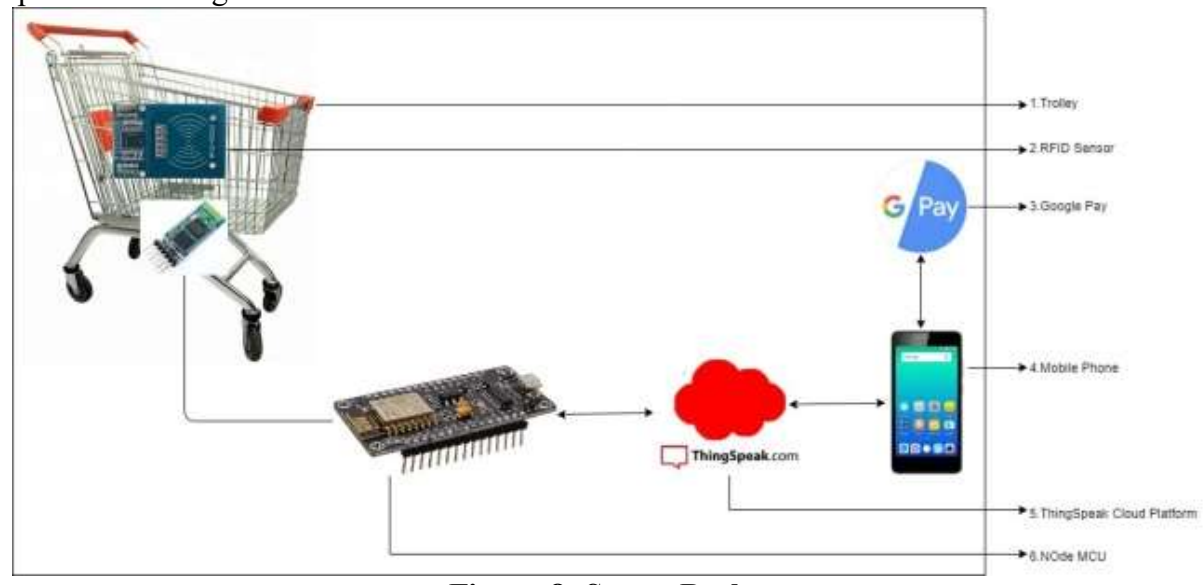

Figure 8: Smart Basket

\section{F. Product 6: Automatic watering the plants}

The aim of this product is to water the plants/crops automatically without wasting the water and to water in time to the plants/crops the water level sensors and moister level sensor and pump was used to detect the requirement of water and to stop the water when it was full. When it was sufficient and value are noted in cloud and can be remote control with the help of the mobile app. 


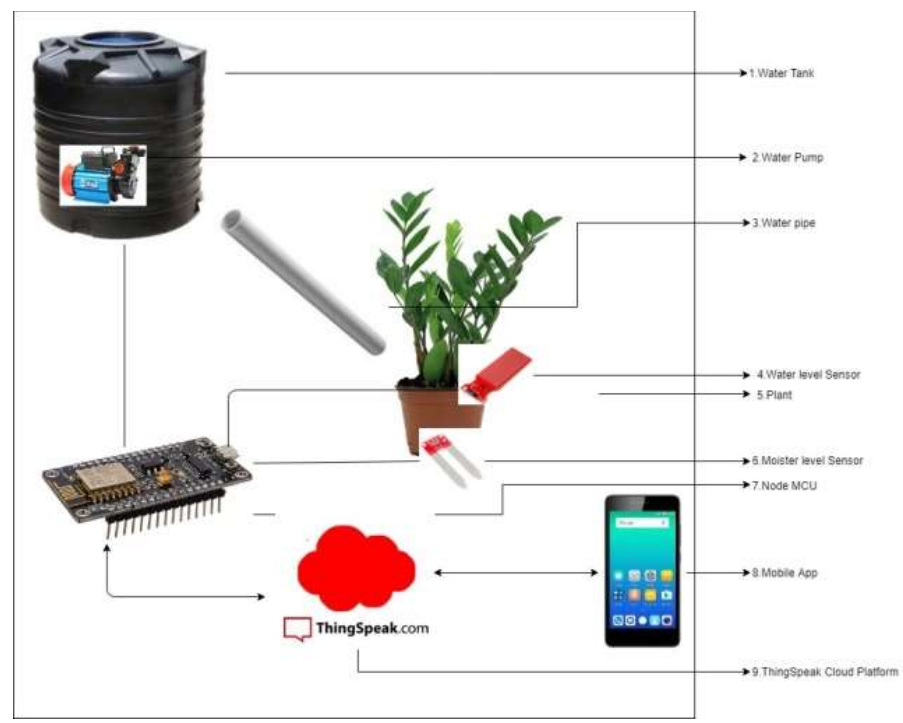

Figure 9: Automatic Watering Plant

\section{Results}

The projects that developed based on the proposed product development cycle was tested in the real time and results were shown in the Table 1

Table 1: Major Features of the Developed Internet of Things (IoT) Products

\begin{tabular}{|l|l|l|l|l|l|}
\hline Product Names/ Features & $\begin{array}{l}\text { Remote } \\
\text { Controlling }\end{array}$ & $\begin{array}{l}\text { Remote } \\
\text { Monitoring }\end{array}$ & $\begin{array}{l}\text { Energy } \\
\text { Saving }\end{array}$ & Automatic & $\begin{array}{l}\text { Time } \\
\text { Saving }\end{array}$ \\
\hline Smart School Bus & YES & YES & No & YES & YES \\
\hline LPG Gas Leakage Detector & YES & YES & No & YES & No \\
\hline Smart ID Card & YES & YES & No & YES & No \\
\hline Smart Basket & YES & YES & YES & YES & YES \\
\hline Smart Switch & YES & YES & YES & YES & YES \\
\hline Automatic Watering Plant & YES & YES & YES & YES & YES \\
\hline
\end{tabular}

\section{Conclusion}

Internet of things was an current technology which has more market value in all over the world it has vast applications almost each and every field like health care, agriculture, transportation, smart home etc.. to develop this kind of applications many startups has been evolved this paper proposed a novel development cycle to develop the IOT applications and some applications was discussed in detail. For this startup companies this paper will help to develop the products by using proposed development cycle.

\section{References}

1. Mayzaud, Anthea, Remi Badonnel, and Isabelle Chrisment. "A Taxonomy of Attacks in RPL-based Internet of Things." International Journal of Network Security 18.3 (2016): 459-473.

2. Evans, Dave. "The internet of things: How the next evolution of the internet is changing everything." CISCO white paper1.2011 (2011): 1-11.

3. Caputo, Andrea, Giacomo Marzi, and Massimiliano Matteo Pellegrini. "The internet of things in manufacturing innovation processes: development and application of a conceptual framework." Business Process Management Journal 22.2 (2016): 383-402.

4. Westerlund, Mika, Seppo Leminen, and Mervi Rajahonka. "Designing business models for the internet of things." Technology Innovation Management Review (2014): 5-14.

5. Gómez, Jorge, et al. "Interaction system based on internet of things as support for education." Procedia Computer Science21 (2013): 132-139.

6. Gershenfeld, Neil, and J. P. Vasseur. "As objects go online; the promise (and pitfalls) of the internet of things." Foreign Aff.93 (2014): 60. 